\title{
Bond Indices in Dihydrogen Bonds
}

\author{
Myriam M. Segre de Giambiagi ${ }^{*, a}$ and Patrick Bultinck ${ }^{b}$
}

${ }^{a}$ Centro Brasileiro de Pesquisas Físicas, R. Xavier Sigaud 150, 2290-180 Rio de Janeiro-RJ, Brazil

${ }^{b}$ Department of Inorganic and Physical Chemistry, Ghent University, Krijgslaan 281, B-9000 Gent, Belgium

\begin{abstract}
Os índices de ligação de três centros levam a uma descrição nova da ligação di-hidrogênio XH...H `M como sendo uma superposição de uma ponte de hidrogênio usual XHH', mais uma

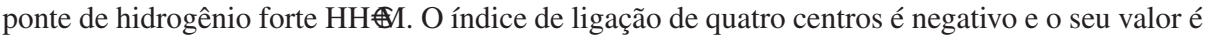
intermediário entre os anteriores.
\end{abstract}

Three-center bond indices lead to a new description for dihydrogen bonds XH...H M: it may be mainly described as a superposition of a usual hydrogen bond XHH ${ }^{`}$ and a strong hydrogen bond $\mathrm{HH}^{\mathrm{M}} \mathrm{M}$. The four-center bond index is negative and its value is intermediate between the preceding ones.

Keywords: dihydrogen bonds, multicenter bond index

\section{Introduction}

Dihydrogen bonds have deserved plenty of attention in the literature of the last ten years. ${ }^{1-8}$ The first appropriate references belong certainly to the Crabtree group. ${ }^{9-12}$ Doubts have been raised around the possibility of an interaction between protonic and acidic hydrogens, which today would be named a dihydrogen bond, hinted as early as $1934 ;{ }^{13}$ as only heavy atoms positions could be actually predicted, the authors postulated a PH...HN interaction. Recently, the ammonium hypophosphite structure has been examined again with a modern diffractometer equipped with a CCD detector, of much higher resolution; this has revealed only conventional $\mathrm{NH}$... O bonds and no close H...H contacts, in agreement with the theoretical study. ${ }^{14}$ It seems well established that this unusual type of hydrogen bonding involves a hydridic-to-protonic interaction, with strength and directionality properties in some respects very similar to those of conventional hydrogen bonds. ${ }^{4,15}$ The hydridic hydrogen comes usually from a metal hydride, so that the dihydrogen bond is written as $\mathrm{XH}$...H $\mathrm{M}$, where $\mathrm{XH}$ is the proton donor. Kulkarni ${ }^{16}$ has also found stationary structures of several dihydrogen bonded complexes, extending to third-row complexes, which are found weaker than the preceding ones. ${ }^{17}$

\footnotetext{
*e-mail: rio@cbpf.br
}

We desire to propose here a somewhat different approach to the problem, through the molecular orbital multicenter bond index. Several years ago, such an index was proposed, discriminating very satisfactorily between strong and usual hydrogen bonds. ${ }^{18}$ In H-bonds, negative values were always obtained for the index. The origin of this negative sign has been extensively analyzed in the literature, ${ }^{19-22}$ being there associated to electron-rich molecules and the bond, particularly, linked to the three-center four-electron (3c-4e) model. In a treatment employing Grassmann algebra, the index has been also related to the correlation between the fluctuations of the charges in each atomic center from their average values. ${ }^{23}$ The multicenter bond index has been the subject of more general treatments through the formalism of Generalized Population Analysis. ${ }^{20,24,25}$ Returning to dihydrogen bonds, among the many theoretical treatments, Grabowski et al. ${ }^{6,26-30}$ have performed heavy ab initio calculations with different basis, obtaining binding energies with their decomposition, together with the topological parameters derived from the Bader theory of atoms in molecules, AIM. ${ }^{31}$ Alkorta et al. ${ }^{32}$ have calculated a number of dihydrogen complexes, showing their binding energies and harmonic vibrational frequencies; in many of them the MH`stretching frequency is blue-shifted. Recently, extremely short contacts have been found for certain small systems involving the $\mathrm{H}_{2} \mathrm{OH}^{+} \cdot \cdots \mathrm{HBeH}$ dimer and its derivatives. ${ }^{6} \mathrm{~A}$ most recent systematic study carried out by the Alkorta-Elguero group ${ }^{8}$ involves the dihydrogen 
bonds formed between $\mathrm{YH}(\mathrm{Y}=\mathrm{Li}, \mathrm{Na}, \mathrm{BeH}, \mathrm{MgH})$ and the three weak hydrogen bond donors $\mathrm{NCH}, \mathrm{CNH}, \mathrm{HCCH}$; different schemes for the interactions are proposed, their conclusion being that the dihydrogen bond is just another type of hydrogen bond.

We shall focus our attention on the pertinent three- and four-center ( $3 c$ and $4 c$ ) bond indices for the complexes appearing in references 28 and 32 . The present ones are the first reported results for bond indices in dihydrogen bonds. In doubtful situations such as those mentioned in reference 15 , the multicenter bond indices may provide other possible elements in order to diagnose dihydrogen bonds.

\section{Multicenter Bond Index}

The first order density matrix in non-orthogonal basis is the product of the charge- bond order matrix $\mathrm{P}$ and the overlap matrix S. For closed-shell systems, its idempotency has led to the corresponding generalization ${ }^{33,34}$ of the Wiberg bond index $\mathrm{I}_{\mathrm{AB}}$ between atoms $\mathrm{A}$ and $\mathrm{B} .{ }^{35}$

$$
\mathrm{I}_{\mathrm{AB}}=4 \sum_{\mathrm{a} \in A} \sum_{\mathrm{b} \in B}(\mathrm{PS})_{\mathrm{ab}}(\mathrm{PS})_{\mathrm{ba}}
$$

The index is known to be related to the exchange energy ${ }^{36}$ and has been extended to open shells. ${ }^{37}$ It is also closely related to effective pair populations and AIM quantities. ${ }^{38}$

The electronic charge $\mathrm{q}_{\mathrm{A}}$ is

$\mathrm{q}_{\mathrm{A}}=1 / 2\left(\mathrm{I}_{\mathrm{AA}}+\sum_{\mathrm{B} \neq A} \mathrm{I}_{\mathrm{AB}}\right)$

The $3 \mathrm{c}$ bond index $\mathrm{I}_{\mathrm{ABC}}$ is similarly written as ${ }^{18}$

$\mathrm{I}_{\mathrm{ABC}}=8 \sum_{\mathrm{a} \in A} \sum_{\mathrm{b} \in B} \sum_{\mathrm{c} \in C}(\mathrm{PS})_{\mathrm{ab}}(\mathrm{PS})_{\mathrm{bc}}(\mathrm{PS})_{\mathrm{ca}}$

Multicenter bond indices are thus, more generally, written as ${ }^{39}$

$\mathrm{I}_{\mathrm{ABC} \ldots \mathrm{K}}=\eta \sum_{\mathrm{a} \in A} \sum_{\mathrm{b} \in B} \ldots \sum_{\mathrm{k} \in K} \sum_{i} \Gamma_{\mathrm{i}}(\mathrm{PS})_{\mathrm{ab}}(\mathrm{PS})_{\mathrm{bc}} \ldots(\mathrm{PS})_{\mathrm{ka}}$

where $\mathrm{H}$ is an appropriate normalization constant and ' ${ }_{\mathrm{i}}$ the permutation operator that interchanges the basis functions labels so as to ensure that the index includes all the terms required.

It may be written ${ }^{40}$

$\mathrm{I}_{\mathrm{AB}}=\lambda \sum_{C} \mathrm{I}_{\mathrm{ABC}}$

where $L$ is an appropriate scaling factor. ${ }^{20}$

A $3 \mathrm{c}$ bond thus contributes to the usual bonds. As in the above formula $\mathrm{C}$ may be equal to $\mathrm{A}$ and $\mathrm{B}$, in a molecule $\mathrm{ABC}$ we have
$\mathrm{I}_{\mathrm{AB}} \mathrm{S} \mathrm{I}_{\mathrm{AAB}}+\mathrm{I}_{\mathrm{ABB}}+\mathrm{I}_{\mathrm{ABC}}$

The first two terms correct the equipartition of the Mulliken charge, ${ }^{41}$ while the last one indicates whether a $3 \mathrm{c}$ bond shall contribute to lengthening (if negative) or shortening (if positive) the bond $\mathrm{AB}$. Thus, it is clearly understood why a molecule like $\mathrm{CO}_{2}$ has a negative $3 c$-index, for carbon monoxide exhibits a shorter interatomic distance; similarly, $\mathrm{C}_{3}$ having always a positive $3 \mathrm{c}$-index, its $\mathrm{CC}$ distance is shorter than the corresponding one in ethylene, the usual reference..$^{21,42}$

Likewise, the well known strong hydrogen bonds in diborane and $(\mathrm{FHF})^{\square}$ have respectively positive and negative values; the $\mathrm{BH}$ distances in the diborane bridge are of course shorter than the others, while the FH distance in the mentioned ion is appreciably longer than the one in hydrogen fluoride.

In a dihydrogen complex $\mathrm{X} \square \mathrm{H} \cdot \cdots \mathrm{H} \square \mathrm{M}$, we have

$\left.\mathrm{I}_{\mathrm{XH}}=\mathrm{L} \square \mathrm{I}_{\mathrm{XXH}}+\mathrm{I}_{\mathrm{XHH}}\right)+\mathrm{L}\left(\mathrm{I}_{\mathrm{XHH}^{\circ}}+\mathrm{I}_{\mathrm{XHM}}\right)$

$\mathrm{I}_{\mathrm{MH}}=\mathrm{L}\left(\mathrm{I}_{\mathrm{MH} \mathrm{H}^{\prime}}+\mathrm{I}_{\mathrm{MMH}}\right)+\mathrm{L}\left(\mathrm{I}_{\mathrm{HH} \mathrm{M}^{\prime}}+\mathrm{I}_{\mathrm{XH} \mathrm{M}^{\prime}}\right)$

Hence one would expect a priori that the signs of the $3 \mathrm{c}$ bonds should indicate whether the $\mathrm{XH}$ and $\mathrm{MH}$ `bonds shall be longer or shorter than the monomers distances. If longer, as happens in usual hydrogen bonds, the bond stretching frequency will be red-shifted; if shorter, it will be blue-shifted.

Now, the blue shift in hydrogen bonds XH...Y has been the subject of very harsh discussions. Schlegel et al. ${ }^{43}$ have carried out the most thorough and complete study of the physical origin of blue-shifted hydrogen bonds. They have shown that not only carbon as a proton donor leads to a blue-shift, but that also molecules involving $\mathrm{Si}, \mathrm{N}$ or $\mathrm{P}$ show substantial blue-shifts. They conclude that blue-shift means $\mathrm{X} \square \mathrm{H}$ contraction and vice versa; despite this conclusion has been objected and attributed to insufficient extension of the basis used in the calculation, ${ }^{44}$ we think that the mentioned study is very clear and the discussion developed takes into account all the factors involved. Alkorta et al. ${ }^{32}$ have found blue shifts for the $\mathrm{M} \square \mathrm{H}$ 'frequency in several of the complexes they studied, we shall return on their results in the discussion. Cybulski et al ${ }^{45}$ have studied some dihydrogen complexes with a variety of approximations; the blue-shift found by them for HCCH...HLi agrees well with that of Alkorta et al.

\section{Results and Discussion}

The calculations have been carried out in two stages. First, geometry has been optimized with a MP2/6- 
$311++\mathrm{G}^{* *}$ basis. The indices are then calculated in the Hartree-Fock approximation and with a more modest basis, 6-31G*. Beyond the Hartree-Fock level, a number of difficulties arise when bond indices are calculated; ${ }^{46}$ other equivalent objections may be raised against the use of DFT approaches: strictly speaking, the two-particle density matrix would be required, while DFT provides only the first order density which, nevertheless, turns to work quite efficiently. ${ }^{47}$ Besides, the definition used with fairly diffuse basis functions may lead to nonsensical values for the bond indices.

For typical hydrogen bonds the values calculated following the same procedure are
$\left(\mathrm{OH}_{2}\right)_{2} \mathrm{I}_{\mathrm{OHO}}=-0.01177 ;(\mathrm{FH})_{2} \mathrm{I}_{\mathrm{FHF}}=-0.00577 ;$

$(\mathrm{FHF})^{-} \mathrm{I}_{\mathrm{FHF}}=-0.12823 ;(\mathrm{ClHF})^{-} \mathrm{I}_{\mathrm{ClHF}}=-0.06781$

Table 1 shows distances, indices and bond energy for dihydrogen bonds between FH and small metal hydrides, together with the corresponding bond energy as reported by Grabowski, ${ }^{28}$ the monomers bond distances appear in the lower part. We show in Table 2 the same quantities, in addition to the MH stretching frequency; this one and bond energy are taken from reference 32. As in this reference, we have calculated the dimers with water. However, we do not report them, for their geometry excludes the formation of a dihydrogen bond. Despite early studies predicted strongly

Table 1. Distances $r(\AA)$, three- and four-center bond indices I and bond energy $E\left(\mathrm{kcal} \mathrm{mol}^{-1}\right)$ for dihydrogen bonds between $\mathrm{FH}$ and small metal hydrides

\begin{tabular}{|c|c|c|c|c|c|c|c|c|}
\hline System & $r_{\mathrm{XH}}$ & $\mathrm{r}_{\mathrm{H}^{\prime} \mathrm{M}}$ & $\mathrm{I}_{\mathrm{XHM}}$ & $\mathrm{I}_{\mathrm{XHH}}$ & $\mathrm{I}_{\mathrm{HH}^{\prime} \mathrm{M}}$ & $\mathrm{I}_{\mathrm{XH} \cdot \mathrm{M}}$ & $\mathrm{I}_{\mathrm{XHH} M}$ & $-E^{28}$ \\
\hline $\mathrm{FH} \cdots \mathrm{H}^{\prime} \mathrm{Li}$ & 0.951 & 1.583 & -0.0240 & -0.0202 & 0.0742 & 0.0051 & -0.0363 & 12.6 \\
\hline $\mathrm{FH}{ }^{\prime} \mathrm{H}^{\prime} \mathrm{Na}$ & 0.959 & 1.898 & -0.0240 & -0.0265 & 0.0706 & 0.0058 & -0.0401 & 13.8 \\
\hline FH'”'B'BeH & 0.923 & 1.327 & -0.0091 & -0.0014 & 0.0356 & -0.0019 & -0.0138 & 2.9 \\
\hline $\mathrm{FH}{ }^{\prime} \mathrm{H}^{\prime} \mathrm{MgH}$ & 0.931 & 1.702 & -0.0134 & -0.0019 & 0.0499 & -0.0021 & -0.0235 & 6.0 \\
\hline FH & 0.917 & & & & & & & \\
\hline $\mathrm{HLi}$ & & 1.599 & & & & & & \\
\hline $\mathrm{HNa}$ & & 1.908 & & & & & & \\
\hline $\mathrm{HBeH}$ & & 1.328 & & & & & & \\
\hline $\mathrm{HMgH}$ & & 1.704 & & & & & & \\
\hline
\end{tabular}

Table 2. Distances $r(\AA)$, three- and four-center bond indices I, bond energy $E\left(\mathrm{kcal} \mathrm{mol}^{-1}\right)$ and $\mathrm{M} \square \mathrm{H}$ stretching frequency $\mathrm{N}\left(\mathrm{cm}^{-1}\right)$ for some dihydrogen bonded systems

\begin{tabular}{|c|c|c|c|c|c|c|c|c|c|}
\hline System & $\mathrm{r}_{\mathrm{XH}}$ & $\mathrm{r}_{\mathrm{H}^{\prime} \mathrm{M}}$ & $\mathrm{I}_{\text {ХHм }}$ & $\mathrm{I}_{\mathrm{XHH}}$ & $\mathrm{I}_{\mathrm{HH}^{\prime} \mathrm{M}}$ & $\mathrm{I}_{\mathrm{XH} \cdot \mathrm{M}}$ & $\mathrm{I}_{\mathrm{XHH} M}$ & $-E^{32}$ & $\mathrm{~N}^{2}$ \\
\hline $\mathrm{NCH} \cdots \mathrm{H}^{\prime} \mathrm{Li}$ & 1.087 & 1.596 & -0.0141 & -0.0182 & 0.0631 & 0.0003 & -0.0217 & 8.8 & 1494 \\
\hline $\mathrm{NCH}{ }^{\cdots} \mathrm{H}^{\prime} \mathrm{Na}$ & 1.091 & 1.910 & -0.0145 & -0.0243 & 0.0685 & 0.0009 & -0.0243 & 9.7 & 1253 \\
\hline $\mathrm{FCCH}{ }^{\cdots} \mathrm{H}^{\prime} \mathrm{Li}$ & 1.077 & 1.596 & -0.0087 & -0.0120 & 0.0454 & -0.0031 & -0.0151 & 4.8 & 1471 \\
\hline $\mathrm{ClCCH} \cdots \mathrm{H}^{\prime} \mathrm{Li}$ & 1.076 & 1.597 & -0.0086 & -0.0107 & 0.0482 & -0.0040 & -0.0146 & 5.0 & 1473 \\
\hline $\mathrm{HCCH}{ }^{\cdots} \mathrm{H}^{\prime} \mathrm{Li}$ & 1.075 & 1.596 & -0.0075 & -0.0097 & 0.0431 & -0.0035 & -0.0132 & 4.4 & 1470 \\
\hline $\begin{array}{l}(\mathrm{Li} \mathrm{N} \mathrm{C} \mathrm{H})^{+\ldots} \\
\mathrm{H}^{\prime} \mathrm{Li}\end{array}$ & 1.169 & 1.619 & -0.0448 & -0.0836 & 0.1574 & 0.0078 & -0.0664 & 27.1 & 1765 \\
\hline $\begin{array}{l}(\mathrm{NaNCH})^{+\ldots} \\
\mathrm{H}^{\prime} \mathrm{Li}\end{array}$ & 1.136 & 1.615 & -0.0354 & -0.0575 & 0.1343 & 0.0046 & -0.0521 & 23.7 & 1897 \\
\hline CNH...H'Li & 1.042 & 1.590 & -0.0222 & -0.0176 & 0.0998 & -0.0037 & -0.0325 & 14.2 & 1523 \\
\hline CNH...H'Na & 1.054 & 1.907 & -0.0267 & -0.0274 & 0.1165 & -0.0054 & -0.0411 & 15.8 & 1304 \\
\hline $\mathrm{NCH}$ & 1.069 & & & & & & & & \\
\hline $\mathrm{FCCH}$ & 1.063 & & & & & & & & \\
\hline $\mathrm{ClCCH}$ & 1.064 & & & & & & & & \\
\hline $\mathrm{HCCH}$ & 1.066 & & & & & & & & \\
\hline$(\mathrm{LiNCH})^{+}$ & 1.075 & & & & & & & & \\
\hline$(\mathrm{NaNCH})^{+}$ & 1.074 & & & & & & & & \\
\hline $\mathrm{CNH}$ & 1.001 & & & & & & & & \\
\hline
\end{tabular}


bent dihydrogen bonds, ${ }^{9,10}$ the more recent ones ${ }^{5,8}$ are rather inclined towards a linear structure such as we obtained for the other systems.

The Tables show that the main roles of the $3 \mathrm{c}$ bonds within dihydrogen bonds are those involving the two hydrogens, namely XHH and $\mathrm{HH}^{`} \mathrm{M}$; the second one more than the first one, its absolute value being significantly higher in all the systems studied. The $3 \mathrm{c}$ bond XHM is also significant, in some cases close to XHH', while the XH'M bond is decidedly less important.

The values shown in the Tables make us conclude that the $\mathrm{HH} \mathrm{M}$ bond is clearly a strong $\mathrm{H}$ bond; so appear to be XHM and XHH for the charged species, while most of the XHH 'bonds and some of the XHM bonds tend to be similar to usual $\mathrm{H}$ bonds. Actually, as found in hydrogen bonds, ${ }^{48}$ the indices in the tables go smoothly from strong to usual.

Let us write for $\mathrm{I}_{\mathrm{HH}}$ the expression equivalent to equations (7):

$\left.\mathrm{I}_{\mathrm{HH}}=\mathrm{L}\left(\mathrm{I}_{\mathrm{HHH}^{\prime}}+\mathrm{I}_{\mathrm{HH} \mathrm{H}^{\prime}}\right)+\mathrm{L} \square \mathrm{I}_{\mathrm{XHH}^{\prime}}+\mathrm{I}_{\mathrm{HH}^{\prime} \mathrm{M}}\right)$;

as $\mathrm{I}_{\mathrm{XHH}}$ and $\mathrm{I}_{\mathrm{HH} \text { M }}$ have opposite sign, they have opposite effects. The first one enhances the $\mathrm{HH}^{`}$ bond and the other one makes it weaker, so that the resulting effect is a bond weaker than that of the hydrogen molecule.

In all the present instances, as usually happens in other dihydrogen bonds, the HH 'distance is considerably longer than that of the hydrogen molecule, ranging from $1.3365 \AA$ for $(\mathrm{LiNCH})^{+} \ldots \mathrm{H}^{`} \mathrm{Li}$ to $2.0497 \AA$ in $\mathrm{HCCH} . . . \mathrm{H}^{`} \mathrm{Li}$. The value for $\mathrm{I}_{\mathrm{HH}}$ ranges in turn from 0.2500 to 0.0426 respectively. Also, as usual and expected, $\mathrm{H}$ is positively charged while H`bears a negative net charge. Very recently, the shortest intermolecular H...H contacts ever reported have been predicted to be $(1.0-1.3 \AA)$ for dihydrogen systems between small cations and either $\mathrm{BeH}_{2}, \mathrm{HBeF}$ or $\mathrm{HBeBeH} ;{ }^{6}$ their covalent nature and the details of the H...H interactions are exhaustively discussed. In reference 8 exponential relationships are obtained for the interaction energies plotted $v s \mathrm{HH}^{`}$ distances, in the complexes for the same proton donor molecule. We obtain a linear behaviour for $E v s \mathrm{I}_{\mathrm{HH}}$, not shown here; this is consistent with the exponential one for I $v s r$ found in the original definition of bond indices for non-orthogonal bases. ${ }^{33}$

The signs of the $3 \mathrm{c}$ indices agree well with the behaviour of the $\mathrm{MH}^{`}$ and $\mathrm{XH}$ bonds. While XH bonds exhibit the usual trend, elongating when entering a hydrogen bond, the $\mathrm{MH}$ 'bonds behave in the opposite sense, becoming shorter; this feature has been found by other authors, although not so generally, ${ }^{28,32}$ and hinted at in the present framework. ${ }^{49}$ The trend of the blue-shift points at the same direction, but there is not a clear correlation as that between the indices and the energies.

Figure 1 represents, on one hand $\mathrm{I}_{\mathrm{XHM}}+\mathrm{I}_{\mathrm{XHH}} \pm$ and on the other hand $\mathrm{I}_{\mathrm{HH} M}+\mathrm{I}_{\mathrm{XH} \mathrm{M}}$, as well as $\mathrm{I}_{\mathrm{XHH} M}$, all of them as functions of the bond energy. The first two lines are nearly parallel, which means that the elongating effect and the shortening effect reflected by the indices are closely equivalent in terms of the bond energy. The $4 \mathrm{c}$ index is also a linear function of the energy, its slope being lower.

Similarly to equation 5 , the $3 \mathrm{c}$ indices may be written as sums of the $4 \mathrm{c}$ ones. There is no need to go into the details of lengthy expressions to understand that, $\mathrm{I}_{\mathrm{XHH} M}$ being negative, $\mathrm{I}_{\mathrm{HH} \text { M }}$ would be even higher if there was no $4 \mathrm{c}$ bond, while $\mathrm{I}_{\mathrm{XHH}}$ and $\mathrm{I}_{\mathrm{XHM}}$ become more significant due to the presence of the $4 \mathrm{c}$ bond.

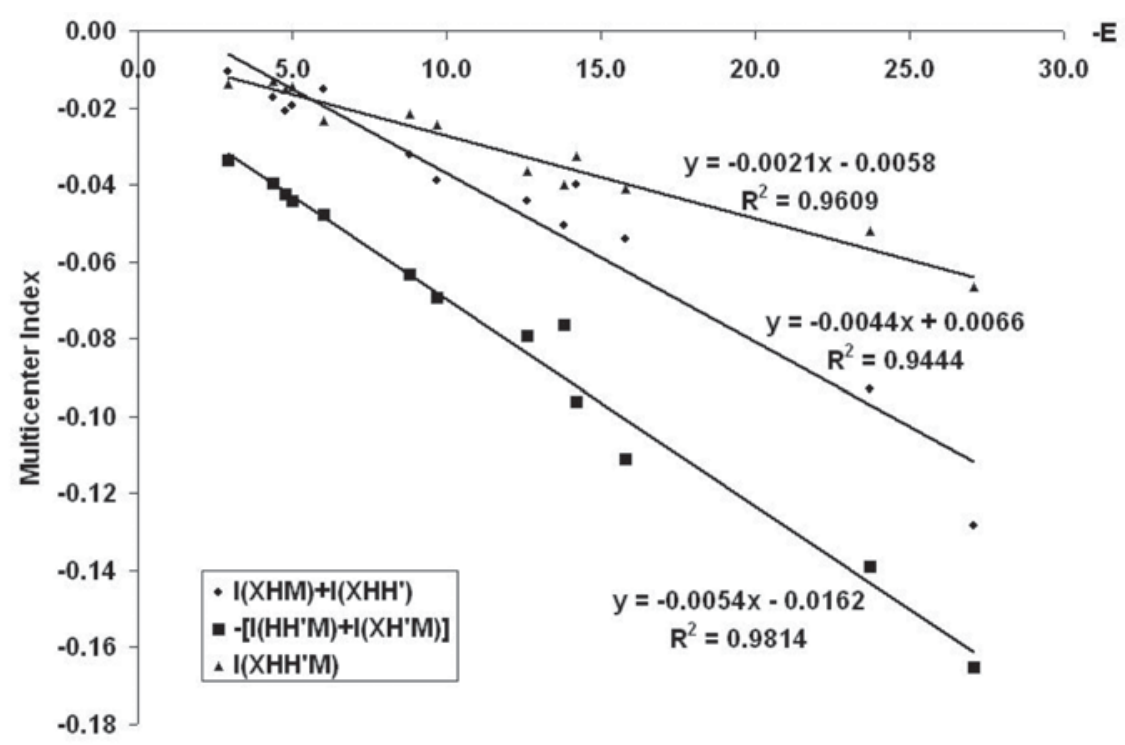

Figure 1. Multicenter bond indices as functions of the bond energy. 


\section{Conclusions}

A dihydrogen bond appears to involve a strong hydrogen bond $\mathrm{HH}^{\mathrm{M}} \mathrm{M}$ plus another usual hydrogen bond XHH'.

Three-center and four-center indices are linearly correlated to the bond energy.

The sign of the three-center indices indicate that in most dihydrogen bonds the $\mathrm{XH}$ bond elongates as in usual hydrogen bonds, while the MH bond most often contracts.

The four-center indices have a value intermediate between those of the XHH ${ }^{`}$ and the $\mathrm{HH}^{`} \mathrm{M}$ bonds.

\section{References}

1. Liu, Q.; Hoffmann, R.; J. Am. Chem. Soc. 1995, 117, 10108.

2. Alkorta, I.; Elguero, J.; Foces-Foces, C.; Chem. Commun. 1996, 1633.

3. Popelier, P. L. A.; J. Phys. Chem. A 1998, 102, 1873.

4. Custelcean, R.; Jackson, J. E.; Chem. Rev. 2001, 101, 1963.

5. Robertson, K. N.; Knop, O.; Cameron, T. S.; Can. J. Chem. 2003, $81,727$.

6. Grabowski, S. J.; Sokalski, W. A.; Leszczynski, J.; J. Phys. Chem. A 2005, 109, 4331.

7. Singh, P. C.; Patwari, G. N.; Chem. Phys. Lett. 2006, 419, 5.

8. Alkorta, I.; Zborowski, K.; Elguero, J.; Solimannejad, M.; J. Phys. Chem. A 2006, 110, 10279.

9. Richardson, T. B.; de Gala, S.; Crabtree, R. H.; J. Am. Chem. Soc. 1995, 117, 12875.

10. Crabtree, R. H.; Siegbahn, P. E. M.; Eisenstein, O.; Reinhold, A. L.; Koetzlee, T. F.; Acc. Chem. Res. 1996, 29, 348.

11. Crabtree, R. H.; J. Organomet. Chem. 1998, 557, 111.

12. Crabtree, R. H.; Science 1998, 282, 2000.

13. Zachariasen, W. H.; Mooney, R. C. L.; J. Chem. Phys. 1934, 2 , 34.

14. Marincean, S.; Custelcean, R.; Stein, R. S.; Jackson, J. E.; Inorg. Chem. 2005, 44, 45.

15. Belkova, N. V.; Shubina, E. S.; Epstein, L. M.; Acc. Chem. Res. 2005, 38, 624 .

16. Kulkarni, S. A.; J. Phys. Chem. A 1998, 102, 7704.

17. Kulkarni, S. A.; Srivastava A. K.; J. Phys. Chem. A 1999, 103, 2836.

18. Giambiagi, M.; Giambiagi, M. M. S.; Mundim, K. C.; Struct. Chem. 1990, 1, 423.

19. Kar, T.; Marcos, E. S.; Chem. Phys. Lett. 1992, 192, 14.

20. Ponec, R.; Mayer, I.; J. Phys. Chem. A 1997, 101, 1738.

21. Sannigrahi, A. B.; Kar, T.; J. Mol. Structure (THEOCHEM) 2000, 496, 1 .

22. Ponec, R.; Yuzhakov, G.; Cooper, D. L.; Theor. Chem. Acc. 2004, 112, 419.
23. Mundim, K. C.; Giambiagi, M.; Giambiagi, M. S.; J. Phys. Chem. 1998, 98, 6118.

24. Ponec, R.; Uhlik, F.; Croat. Chem. Acta 1996, 69, 941.

25. Ponec, R.; Cooper, D. L.; Int. J. Quantum Chem. 2004, 97, 1002.

26. Grabowski, S. J.; Chem. Phys. Lett. 1996, 312, 542.

27. Grabowski, S. J.; J. Mol. Struct. 2000, 553, 151.

28. Grabowski, S. J.; J. Phys. Chem. A 2000, 104, 5551.

29. Grabowski, S. J.; Sokalski, W. A.; Leszczynski, J.; J. Phys. Chem. A 2004, 108, 1806.

30. Grabowski, S. J.; Sokalski, W. A.; Leszczynski, J.; J. Phys. Chem. A 2004, 108, 5823.

31. Bader, R. F. W.; Atoms in Molecules: A Quantum Theory, Clarendon Press: Oxford, 1990.

32. Alkorta, I.; Elguero, J.; Mó, O.; Yánez, M.; Del Bene, J. E.; J. Phys. Chem. A 2002, 106, 9325.

33. Giambiagi, M.; Giambiagi, M. S.; Grempel, D. R.; Heymann, C. D.; J. Chim. Phys. 1975, 72, 15.

34. Giambiagi, M. S.; Giambiagi, M.; Jorge, F. E.; Z. Naturforsch. 1983, 39, 1259.

35. Wiberg, K.; Tetrahedron 1968, 24, 1083.

36. Mayer, I.; Chem. Phys. Lett. 1983, 97, 270.

37. Mayer, I.; Int. J. Quantum Chem. 1986, XXIX, 73.

38. Ponec, R.; Uhlik, F.; J. Mol. Structure (THEOCHEM) 1997, $391,159$.

39. Bultinck, P.; Ponec, R.; Van Damme, S. J.; J. Phys. Org. Chem. 2005, 18, 706

40. Sannigrahi, A. B.; Kar, T. S.; Chem. Phys. Lett. 1990, 173, 569.

41. Giambiagi, M. S.; Giambiagi, M.; Fortes, M. S.; J. Mol. Struct. (THEOCHEM) 1997, 391, 141.

42. Giambiagi, M. S.; Giambiagi, M.; Herrera, J.; Z. Naturforsch. 1994, $49 a, 754$.

43. Li, X.; Liu, L.; Schlegel, H. B.; J. Am. Chem. Soc. 2002, 124, 9639.

44. Domagala, M.; Grabowski, S. J.; J. Phys. Chem. A 2005, 109, 5683.

45. Cybulski, H.; Pecul, M.; Sadlej, J.; Helgaker, T.; J. Chem. Phys. 2003, 119, 5094.

46. Bultinck, P.; Rafat, M.; Ponec, R.; Van Gheluwe, B.; CarbóDorca, R.; Popelier, P.; J. Phys. Chem. A 2006, 110, 7642.

47. Poater, J.; Duran, M.; Solá, M.; Silvi, B.; Chem. Rev. 2005, 105, 3911.

48. Parthasarathi, R.; Subramanian, V.; Sathyamurthy, N.; J. Phys. Chem. A 2006,110, 3349.

49. Giambiagi, M. S.; Oliveira Neto, M.; Finageiv Neder, A. V.; J. Mathem. Chem. 2005, 38, 519.

Received: July 12, 2007

Published on the web: February 22, 2008 